\title{
Taking animal breeding into the wild: regulation of fishing gear can make fish stocks evolve higher productivity
}

\author{
Fabian Zimmermann ${ }^{1,2, *}$, Christian Jørgensen ${ }^{2,3}$ \\ ${ }^{1}$ Institute of Marine Research and Hjort Centre for Marine Ecosystem Dynamics, PO Box 1870 Nordnes, 5817 Bergen, Norway \\ ${ }^{2}$ Department of Biology and Hjort Centre for Marine Ecosystem Dynamics, University of Bergen, PO Box 7803, 5020 Bergen, \\ Norway \\ ${ }^{3}$ Uni Research and Hjort Centre for Marine Ecosystem Dynamics, 5020 Bergen, Norway
}

\begin{abstract}
Harvesting of living resources involves conflicting objectives between profits, human consumption, population sustainability and ecological impacts. These trade-offs are often complex, as harvesting affects demography and productivity of wild populations immersed in rich ecological interactions, and consequences may extend to the evolutionary dimension. In a life-history model of a commercially harvested fish stock, the Northeast Arctic stock of Atlantic cod Gadus morhua, we show how fishing mortality and gear selectivity affect evolution of maturation age, population dynamics and fisheries yield. We focus on common management objectives, and show that taking more of the catch with gillnets that select for intermediate sizes has the potential to increase yield and reverse undesirable evolutionary effects that have taken place over the past century. We compare the high fishing pressure of past decades with the current management plan and alternative scenarios that maximize (1) food production, (2) product quality (size of individual fish in the catch), or (3) evolutionary reversal. Directing more of the catch towards individuals below or at maturation size improves sustainability and food production from fisheries while reversing evolutionary impacts. This demonstrates that evolutionarily enlightened management of size selectivity, based on existing gear types and technology, can reconcile seemingly conflicting management objectives.
\end{abstract}

KEY WORDS: Fisheries management $\cdot$ Gear selectivity $\cdot$ Conflicting objectives · Evolutionary impact assessment $\cdot$ Sustainable fisheries

\section{INTRODUCTION}

In modern society, food production is centered on agriculture, which generates by far the largest quantities of food and has sufficient potential to meet global demand in the future (Erb et al. 2016). Yet the use of wild populations has remained important, both for producing food and for its cultural and recreational value (Chiesura \& de Groot 2003, Chan et al. 2012). Marine fisheries in particular are a relevant

\footnotetext{
*Corresponding author: fabian.zimmermann@imr.no
}

source of human calorie intake and a key protein supply in many countries (FAO 2014, 2016). However, while agriculture aims at controlling its environment and optimizing its productivity through, for example, irrigation, fertilizers, pest control, selective breeding and so on, harvesting wild populations takes place in an uncontrollable environment and has far-reaching, often negative effects on harvested populations and their ecosystems (Gislason 1994, Dayton et al. 1995, Jennings \& Kaiser 1998). This

(C) The authors 2017. Open Access under Creative Commons by Attribution Licence. Use, distribution and reproduction are unrestricted. Authors and original publication must be credited. 
includes impacts on population dynamics and extends to the evolutionary dimension through Darwinian selection of undesired traits, potentially decreasing overall productivity (Law \& Grey 1989, Jørgensen et al. 2007). Supplying mankind with high-quality protein in the future therefore depends on forward-looking management strategies that secure and maximize the utility of renewable resources such as fish.

The most common objective in fisheries management is maximizing sustainable yield (MSY) (Larkin 1977), which has become a paradigm in fisheries and set in stone as a major objective in international agreements (UNCLOS 1982, United Nations 2002). However, MSY is a simplified concept that many argue is deficient because it fails to capture the ecological and political complexity of managing marine ecosystems (e.g. Finley \& Oreskes 2013). Typically, a diversity of stakeholders disagree on optimal use of fish stocks and their environment, and conflicting objectives are a fundamental challenge for fisheries management (Hilborn 2007, Costello et al. 2016). Practical fisheries management therefore has to strike a balance between various ecosystem services produced by living marine resources, notably food production, economic benefits, socio-economic objectives such as employment, or the conservation of fish stocks and their ecosystems.

As harvesting methods differ in their selectivity, e.g. in terms of size, behavior, morphology, or simply area of deployment, gear selectivity may be used purposely to target fish with specific characteristics and is therefore a classic tool in fisheries management (Cochrane \& Garcia 2009). Particularly, spatial and temporal restrictions or minimum size limits have been widely used as a simple input control with the aim of increasing yield or revenue while safeguarding productivity, sustainability, other species and habitats. Size selectivity is usually determined by mesh size (Hamley 1975) and the gear type (Watson et al. 2006). Common fishing gear includes trawls and seines, which display a sigmoid size-selectivity curve that catches all fish above a specific size, and gillnets, typically with dome-shaped selectivity that excludes fish below and above a target size range.

The degree to which the various ecosystem services are impacted by fishing often hinges on biological detail and the harvesting method. For example, stock biomass is composed of individuals that can differ widely in their numbers, sizes and traits (Murawski et al. 2001), and fishing particularly diminishes the abundance of older age classes, which may have higher reproductive output (Hixon et al. 2014), thus potentially reducing productivity and amplifying fluctuations (Berkeley et al. 2004b, Hsieh et al. 2006, Ottersen et al. 2006). A more recent concern is that fishing mortality imposes Darwinian selection on phenotypic traits and can therefore result in evolutionary change (Law 2000, Hutchings \& Fraser 2008), often more so when fishing gear is selective on size or other traits. Over time, such fishing-induced evolutionary change could potentially decrease stock biomass and sustainable yield (Law \& Grey 1989, Conover \& Munch 2002). Consequently, there are widespread calls to manage the effects of selective fishing on age structure (Birkeland \& Dayton 2005, Francis et al. 2007, Zhou et al. 2010) and trait evolution (Kuparinen \& Merilä 2007, Heino et al. 2013, Laugen et al. 2014). Besides an overall reduction of fishing mortality, common suggestions involve less selectivity (Garcia et al. 2012, Law et al. 2012) or a shift in selection patterns to reduce harvest pressure on big, old fish (Law 2000, Hixon et al. 2014).

In this study we analyse whether gear selectivity can be used as a management tool to align the management targets of reducing evolutionary impacts and MSY. To do so, we focus on the options available to contemporary fisheries management and assume an overfished stock where traits have already evolved to early maturation, as observed in many commercial fisheries (Jørgensen et al. 2007). One of the few remedies suggested to ameliorate negative evolutionary impacts is to reduce fishing mortality (Law 2007); however, substantial reductions of the catch may lead to socio-economic repercussions in the short term. As a complementary management tool, we assess how the type of gear used (gillnets with bell-shaped size selectivity versus trawls with sigmoid selectivity) impacts stock state, evolving maturation age and yield. Our study builds on previous research that explored the role of gear selectivity within an evolutionary context (Hutchings 2009, Jørgensen et al. 2009); however, here we study evolution of life-history traits and consequences for population dynamics and fisheries yield on timescales relevant to the fisheries manager. The goal is to provide insights into how management of size-selective fishing could mitigate and even reverse the evolutionary impact of fishing, improve the stock state and increase sustainable yield. The novelty of the present study is to provide an integrated perspective on combined evolutionary and non-evolutionary dynamics and focus on resulting management tradeoffs within a short-term perspective relevant to fisheries management. 


\section{METHODS}

\section{Model description}

The model is parameterized to resemble the Northeast Arctic stock of Atlantic cod Gadus morhua and expands on the model of Zimmermann \& Jørgensen (2015) with size-selective fishing and densitydependent growth. Maturation age is a key lifehistory trait in most fish species, because the onset of maturation leads to a shift in energy investment from growth to reproduction and therefore determines lifetime trajectories of growth, survival and reproduction, which again affects population dynamics, stock productivity and yield. The selection acting on maturation age originates from natural and fishing mortality, both of which are size-selective.

The model assumes that age at maturation is a genetically coded trait, following quantitative inheritance. From maturation onwards, growth is decreased (Fig. S1 in the Supplement at www.int-res.com/articles/suppl/ m563p185_supp.pdf) as ingested resources become allocated to gonads and reproduction (Rijnsdorp 1993). Individuals with a low maturation age will have small size-at-age and low fecundity, while fish maturing later in life will be bigger and more fecund. Mortality, including fishing, represents the main source of selection and leads to adaptation over time. As in eco-genetic models (Dunlop et al. 2009), fitness, inheritance and trait evolution emerge from within the model and are not based on pre-defined fitness functions. This allows us to study evolutionary trajectories and not just endpoints of evolution. However, in contrast to eco-genetic modelling, we focus on one instead of several evolving traits and their interplay, thus enabling a tractable tool that is easier to analyse and interpret.

In brief, we use a model with genetic and phenotypic structure and keep track of phenotypes by their age class $a$. Age classes may vary in their distribution of genotype $g$, which codes for maturation age. Our assumptions follow the theory of quantitative genetics, assuming that a trait is determined by an infinite number of loci, each with a small additive effect (Lynch \& Walsh 1998, Dunlop et al. 2009). The expressed phenotypic maturation age $m$ is normally distributed around $g$ to represent non-additive genetic and environmental effects. Demographic processes may cause differential survival (and growth and reproduction) between different phenotypes emerging from the same genotype.

A biphasic growth model (Quince et al. 2008, Boukal et al. 2014) that includes density dependence determines growth and hence individual length-atage (see also Fig. S1):

$$
L_{t}(a, m)=\sqrt[b_{1} \cdot b_{2}]{\frac{L_{t}(a-1, m)^{b_{1} \cdot b_{2}}+b_{2} \cdot c(t) \cdot b_{3}^{-b_{2}}}{1+b_{2} \cdot Q(a, m)}}
$$

with $C(t)=1-d \cdot\left[\left(S S B_{t} / S S B_{0}\right)-1\right]$ as the densitydependent growth coefficient at time $t$, determined by the density dependence coefficient $d$ and the ratio between the total mature biomass $S S B_{t}$ at $t$ and the pristine mature biomass $S S B_{0}$. Parameters $b_{1}$ and $b_{3}$ follow from the allometric relationship between somatic weight $W$ and length $W_{t}=b_{3} \cdot L_{t}^{b_{1}} \cdot Q(a, m)$ is gonadosomatic index and represents reproductive investment; it is 0 for $a<m$ and the target gonadosomatic index $q$ above that unless constrained by the maximum value of $c \cdot L_{t}(a, m)^{-b_{1} \cdot b_{2}} \cdot b_{3}{ }^{-b_{2}}$, as implied by Eq. (1). The gonadosomatic index is the weight ratio between gonads and somatic weight, therefore gonad weight is $G(a, m)=Q(a, m) \times W_{t}(a, m)$.

The population is structured by age $a$, phenotypic maturation age $m$, and genotype $g_{i}$ we thus denote abundance at time $t$ as $N_{t}=\int_{a} \int_{m} \int_{g} N_{t}(a, m, g)$, where $N_{t}(a, m, g)$ is the abundance of individuals with state combination $a, m$ and $g$. Survival $S_{t}(a, m)$, accounting for fishing and natural mortality (see below), determines the number of individuals that progress from one age to the next:

$$
N_{t+1}(a+1, m, g)=N_{t}(a, m, g) \cdot S_{t}(a, m)
$$

Abundance of $a=0$ is generated through reproduction following a density-dependent BevertonHolt recruitment function:

$$
N_{0, t+1}=\frac{\alpha \cdot G_{t}}{1+\beta \cdot G_{t}}
$$

Here $G_{t}$ is the summed weight of gonads in the population at the end of the time step. Reproduction is assumed to be sexual and based on random mating with no differentiation between males and females. The genetic composition of the newborn cohort is determined by the midparental value of the genetic maturation age across possible parent pairs, plus added variance due to mutation, segregation and recombination (for details see Zimmermann \& Jørgensen 2015).

Crucial in this model is how size-dependent natural and fishing mortality determine survival, thus leading to selection and adaptation. Natural mortality is defined as

$$
M(a, m)=M_{0}+M_{1} \cdot\left(\frac{L(a-1, m)+L(a, m)}{2}\right)^{-M_{2}}
$$

where parameters $M_{1}$ and $M_{2}$ describe the level and scaling of the size-dependent component, 
using the average length at the beginning and the end of the year. A base natural mortality $M_{0}$ aligns the resulting natural mortality (Fig. S2) for older fish $(a \geq 3 \mathrm{yr})$ to stock assessment estimates (ICES 2015).

Fishing is size-selective and based on gillnet-like (Eq. 5; specific gillnet selectivities shown in Fig. S2) and trawl-like (Eq. 6) fishing patterns. Gillnet-like selectivity curve $k_{\gamma}$ is defined as:

$$
k_{\gamma, t}(a, m)=\mathrm{e}^{-\left(\frac{\frac{L_{t}(a-1, m)+L_{t}(a, m)}{2}-L_{\max }}{2 \cdot\left(s_{\gamma} \cdot L_{\max }\right)^{2}}\right)^{2}}
$$

To increase comparability, instead of a classic sigmoid function for trawl selectivity we introduce a modified trawl-like (Eq. 6) selectivity curve $k_{\tau}$ (based on Eq. 5):

$$
k_{\tau, t}(a, m)=\left\{\begin{array}{cc}
k_{\gamma, t}(a, m), & L_{t}(a, m)<L_{\max } \\
1, & L_{t}(a, m) \geq L_{\max }
\end{array}\right.
$$

This assumes that selectivity increases with size like the left half of the dome-shaped curve, then remains at maximum for larger sizes. The only difference between the 2 selectivity curves is thus whether large fish are harvested or not. $L_{\max }$ is the size at which the selectivity curve peaks and fish become fully vulnerable to fishing, representing the size selectivity of gear determined by mesh sizes.

We set a total allowable catch based on $F_{\text {input }}$ and a pure trawl fishery and then split between 2 different fleets with distinct gear types. This approach emulates a fishery managed through a total allowable catch that is split between 2 different gear types, improving the comparability between fishing regimes that differ in their size selectivity and avoiding biases through deviating total catch under different selectivity regimes. The standardization procedure was as follows: we let the parameter $F_{\text {input }}$ describe the annual fishing mortality of sizes that are fully recruited to a pure trawl fishery, and then set a proportion $o$ of the biomass to be harvested by gillnets. In each time step, the total yield of a pure trawl-like selectivity $(o=0)$ was used to calculate in an iterative process the adequate gear type coefficient $\rho$, fulfilling 2 conditions: (1) the combined yield of trawl and gillnet fishery was equal to the total yield under $o=0$; and (2) the proportion of yield between gillnet- and trawl-like selectivity corresponded to the given $o$. This allowed us to calculate the realized fishing mortality using the gear type coefficient $\rho$ and $F_{\text {input }}$ :

$F_{t}(a, m)=\rho \cdot F_{\text {input }} \cdot k_{y, t}(a, m)+(1-\rho) \cdot F_{\text {input }} \cdot k_{\tau, t}(a, m)$

Together with $M_{t}(a, m)$, the realized catch can be calculated:

$C_{t}(a, m)=\frac{F_{t}(a, m)}{F_{t}(a, m)+M_{t}(a, m)} \cdot N_{t}(a, m, g) \cdot\left(1-\mathrm{e}^{-\left(F_{t}(a, m)+M_{t}\left(a_{1} m\right)\right)}\right)$ and subsequently the catch proportion $\frac{C_{t}(a, m)}{N_{t}(a, m, g)}$ (see Fig. 1a).

All variables and parameter values are detailed in Tables $1 \& 2$, respectively.
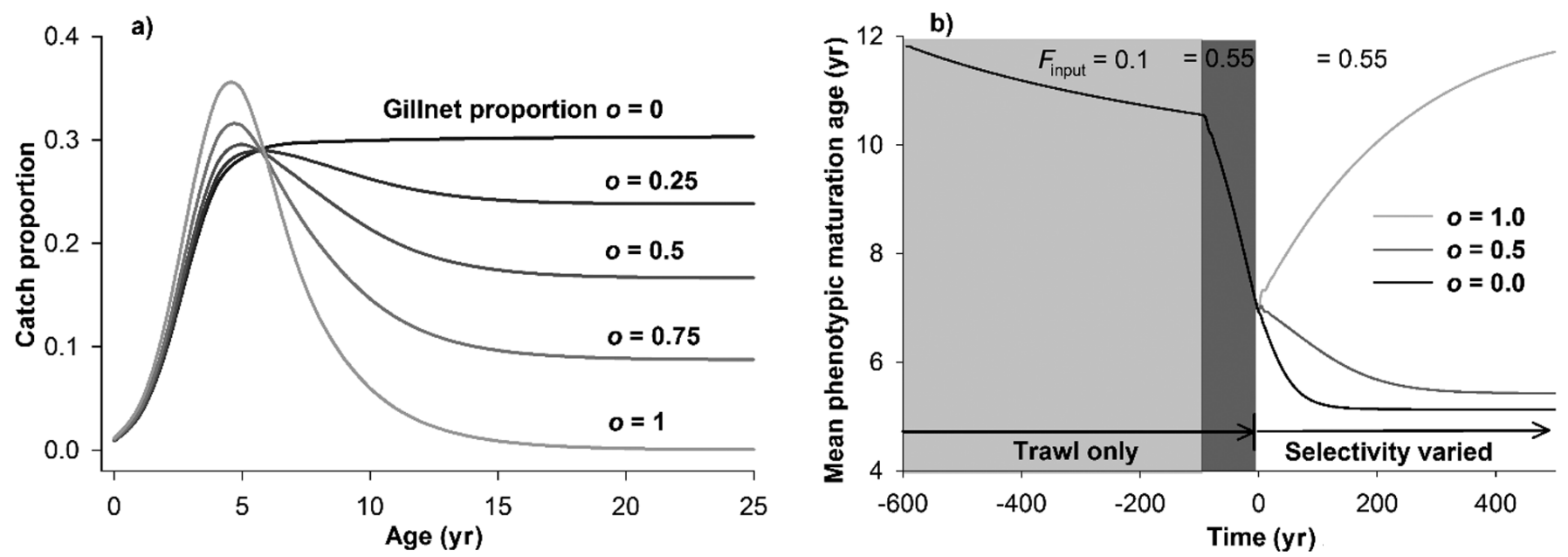

Fig. 1. (a) Catch proportion per age class and (b) long-term simulations of mean phenotypic maturation age over time for varying gear selectivity. Results are shown for pure trawl selectivity $o=0$ (black line) to pure gillnet selectivity $o=1$ (light grey line). Catch proportion (a) is calculated as catch per age class divided by abundance per age class at year $t=100$ with input fishing mortality $F_{\text {input }}=0.55$ and size selectivity $L_{\max }=60 \mathrm{~cm}$. Long-term simulations (b) include calibration periods for a pristine stock (light grey area; $500 \mathrm{yr}$ with $F_{\text {input }}=0.1, L_{\max }=80 \mathrm{~cm}$ and $o=0$ ) followed by intense fishing (dark grey area; $100 \mathrm{yr}$ with $F_{\text {input }}=0.55, L_{\max }=60 \mathrm{~cm}$ and $o=0$ ) and the simulation of varying selectivity regimes (white area; $500 \mathrm{yr}$ with $F_{\text {input }}=0.55$, 
Table 1. Model variables

\begin{tabular}{|lcc|}
\hline Variable & Symbol & Unit \\
\hline Age & $a$ & $\mathrm{yr}$ \\
Maturation age & $\mathrm{m}$ & $\mathrm{yr}$ \\
Individual length & $L(a, m)$ & $\mathrm{cm}$ \\
Individual weight & $W(a, m)$ & $\mathrm{kg}$ \\
Gonad weight & $G(a, m)$ & $\mathrm{kg}$ \\
Individual gonadosomatic index & $Q(a, m)$ & - \\
Natural mortality & $M(a, m)$ & $\mathrm{yr}^{-1}$ \\
Trawl selectivity & $k_{\tau}(a, m)$ & - \\
Gillnet selectivity & $k_{\gamma}(a, m)$ & - \\
Fishing selectivity input variable & $L_{\mathrm{max}}$ & $\mathrm{cm}^{-1}$ \\
Fishing mortality input variable & $F_{\text {input }}$ & $\mathrm{yr}^{-1}$ \\
Gillnet proportion & $o$ & - \\
Gear type coefficient & $\rho$ & - \\
\hline
\end{tabular}

\section{Simulation protocol}

To create starting conditions that correspond to empirical data, the initial population was generated from a 'pristine' population (i.e. fished lightly for $500 \mathrm{yr}$ with $o=0, L_{\max }=80 \mathrm{~cm}$ and $F_{\text {input }}=0.1 \mathrm{yr}^{-1}$ to imitate historic handline fishing on migrating spawners) that was subsequently fished down with $o=0$, $L_{\max }=60 \mathrm{~cm}$ and $F_{\text {input }}=0.55$ (the latter corresponding roughly to the long-term arithmetic mean of fishing mortality in the Northeast Arctic cod fishery) until a mean maturation age of $7 \mathrm{yr}$ was reached, which took ca. 80 yr. This resulted in population characteristics representative of an intensively fished cod stock. Subsequent simulations were performed for a time period of $100 \mathrm{yr}$ with combinations of $o$ and $F_{\text {input }}$ varying within the range 0 to 1 . Age at maturation over the entire calibration and simulation period is shown in Fig. 1b.

\section{RESULTS}

Fishing selectivity strongly affects maturation age, spawning stock biomass (SSB), yield and catch size in the simulated cod stock (Fig. 2). These effects occurred as a direct response to changes in the selectivity regime, became more pronounced over time and depended on the choice of size selectivity $L_{\max }$ the gillnet proportion $o$ and the fishing pressure $F_{\text {input. }}$ Changes in SSB and yield were mainly driven by ecological effects and only slowly modified by evolutionary change, which gained importance in the long run. Phenotypic maturation age evolved as a direct response to $F_{\text {input }}$ as well as to $L_{\max }$ and $o$ combined, which determine how $F_{\text {input }}$ affects different age classes within the stock. Increases in maturation age were largest when high $o$ and intermediate $L_{\max }$ caused high mortality for fish below or at maturation size, while large, mature fish were excluded from the catch, creating selection pressure towards higher maturation age. Overall, evolutionary impacts were reversed and yield maximized with harvest strategies based on high gillnet proportion, small to intermediate target size and high fishing mortality, while low gillnet proportion, large target size and low fishing mortality resulted in the largest SSB and catch sizes (Fig. 2).

Were one to continue with business as usual, i.e. a trawl-dominated fishery with $L_{\max }=60 \mathrm{~cm}$ (Huse et al. 2000, Kvamme \& Isaksen 2004), the model predicted yield curves peaking at $F_{\text {input }}$ between 0.3 and 0.35 , slightly below current estimates of $F_{\mathrm{MSY}}$ in Northeast Arctic cod (ICES 2015). Evolution would continue towards earlier maturation and mean size of the fish in the catch would continue to decline. With

Table 2. Model parameters

\begin{tabular}{|c|c|c|c|}
\hline Parameter & Symbol & Unit & Value \\
\hline Maximum age & $a_{\max }$ & yr & 25 \\
\hline Genotype & $g$ & - & - \\
\hline Standard deviation of non-additive effects & $\operatorname{sd}\left(\delta_{\mathrm{DE}}\right)$ & - & 3 \\
\hline Growth coefficient $^{\mathrm{a}}$ & $C$ & - & 3.4 \\
\hline Exponent of allometric weight-length relationship ${ }^{\mathrm{a}}$ & $b_{1}$ & - & 3.0 \\
\hline Exponent of allometric relationship between resource acquisition rate and weight ${ }^{\mathrm{a}}$ & $b_{2}$ & - & 0.25 \\
\hline Coefficient in allometric weight-length relationship ${ }^{a}$ & $b_{3}$ & - & 0.01 \\
\hline Target gonadosomatic index ${ }^{\mathrm{a}}$ & $q$ & - & 0.3 \\
\hline Length at age $0^{\mathrm{a}}$ & $L_{0}$ & $\mathrm{~cm}$ & 12.5 \\
\hline Base natural mortality & $M_{0}$ & $\mathrm{yr}^{-1}$ & 0.15 \\
\hline Natural mortality coefficient ${ }^{\mathrm{b}}$ & $M_{1}$ & $\mathrm{yr}^{-1}$ & 72.5 \\
\hline Exponent of relationship between individual length and natural mortality ${ }^{\mathrm{b}}$ & $M_{2}$ & $\mathrm{~cm}$ & 1.61 \\
\hline Gillnet selectivity parameter & $s_{\gamma}$ & $\mathrm{cm}^{-1}$ & 0.28 \\
\hline Beverton-Holt recruitment parameter & $\alpha$ & - & 10 \\
\hline Beverton-Holt recruitment parameter & $\beta$ & - & 0.1 \\
\hline${ }^{\mathrm{a}}$ Enberg et al. (2009); ${ }^{\mathrm{b}}$ Gislason et al. (2010) & & & \\
\hline
\end{tabular}


Phenotypic maturation age
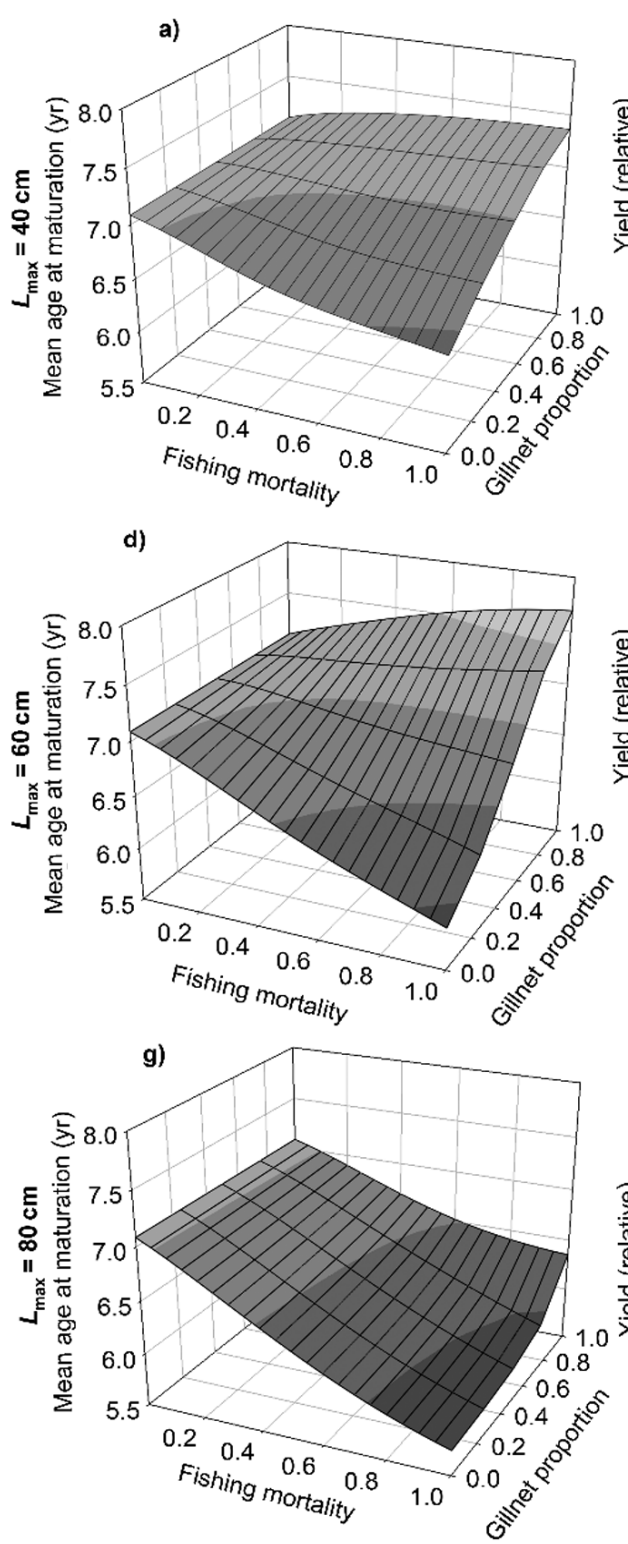
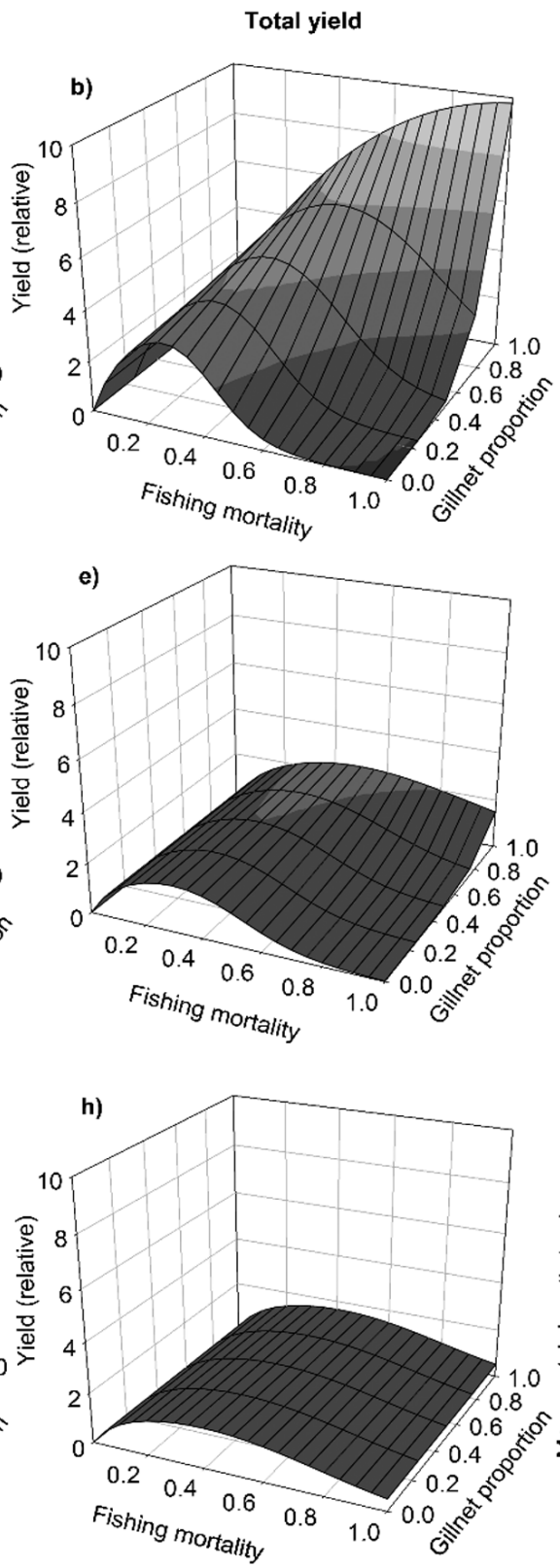

Catch length
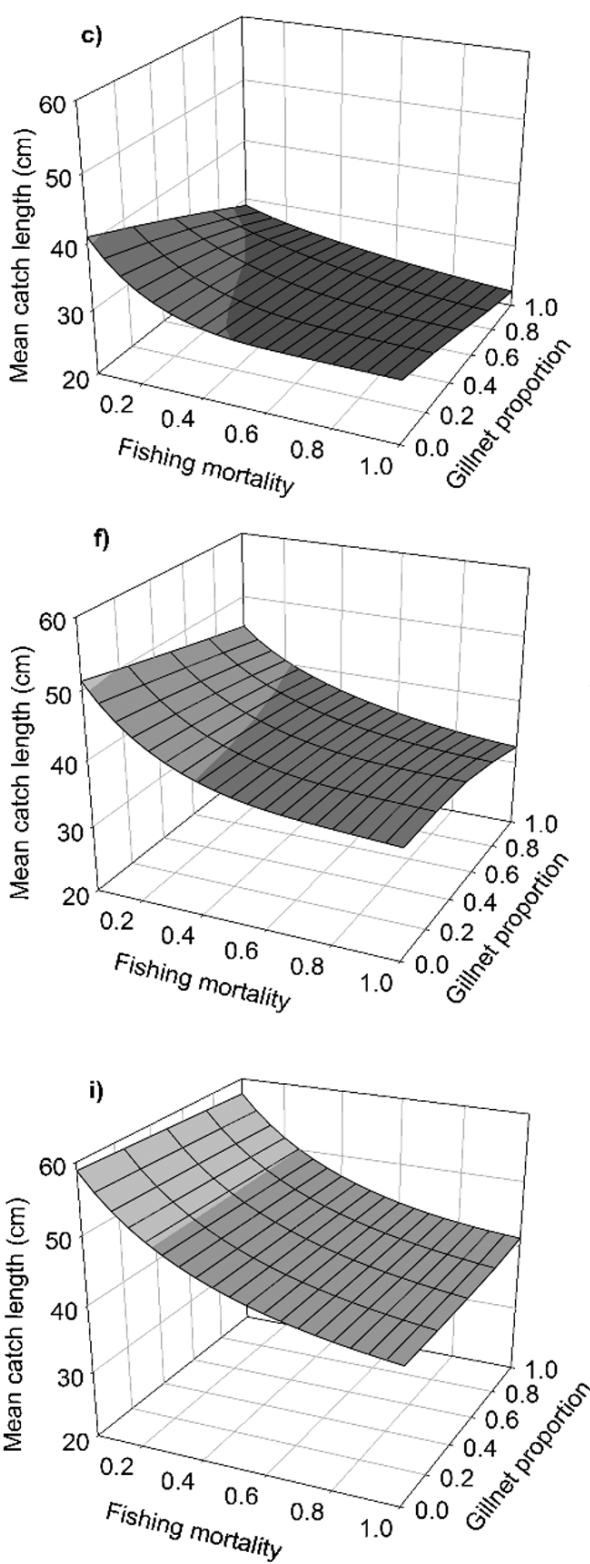

Fig. 2. Mean phenotypic maturation age, total yield and mean length in catch after 20 yr for $(\mathrm{a}, \mathrm{b}, \mathrm{c})$ size selectivity $L_{\text {max }}=$ $40 \mathrm{~cm},(\mathrm{~d}, \mathrm{e}, \mathrm{f}) L_{\max }=60 \mathrm{~cm}$ and $(\mathrm{g}, \mathrm{h}, \mathrm{i}) L_{\max }=80 \mathrm{~cm}$. Total yield is standardized to the value at $t=0 \mathrm{yr}$

the same target size, yield could be increased slightly and maturation evolution reversed by shifting more of the harvesting to gillnets (Fig. 2d,e,f).

The model predicted mostly negative effects of shifting size selectivity to larger sizes $\left(L_{\max }=80 \mathrm{~cm}\right.$, Fig. $2 g, h, i)$ as yield would go down and evolution towards earlier maturation would be faster for most combinations of gear type and fishing intensity. On the positive side, the mean size of fish in the catch was predicted to go up, and the stock would be able to resist higher trawling pressure before collapse (Fig. S3 in the Supplement at www.int-res.com/articles/ suppl/m563p185_supp.pdf).
Under low $L_{\max }(40 \mathrm{~cm})$, however, yield was predicted to increase distinctly under most management strategies, particularly with increasing use of gillnets. SSB, on the other hand, is heavily influenced by the gear composition, with the largest SSB over all management strategies observed for gillnet-dominated fisheries. In this case, the stock also became resilient to higher fishing mortality, and evolution was reversed, albeit more slowly. This was accompanied by the smallest catch sizes compared to other selectivity regimes.

We then attempted to identify harvesting strategies that would score well on multiple objectives while be- 

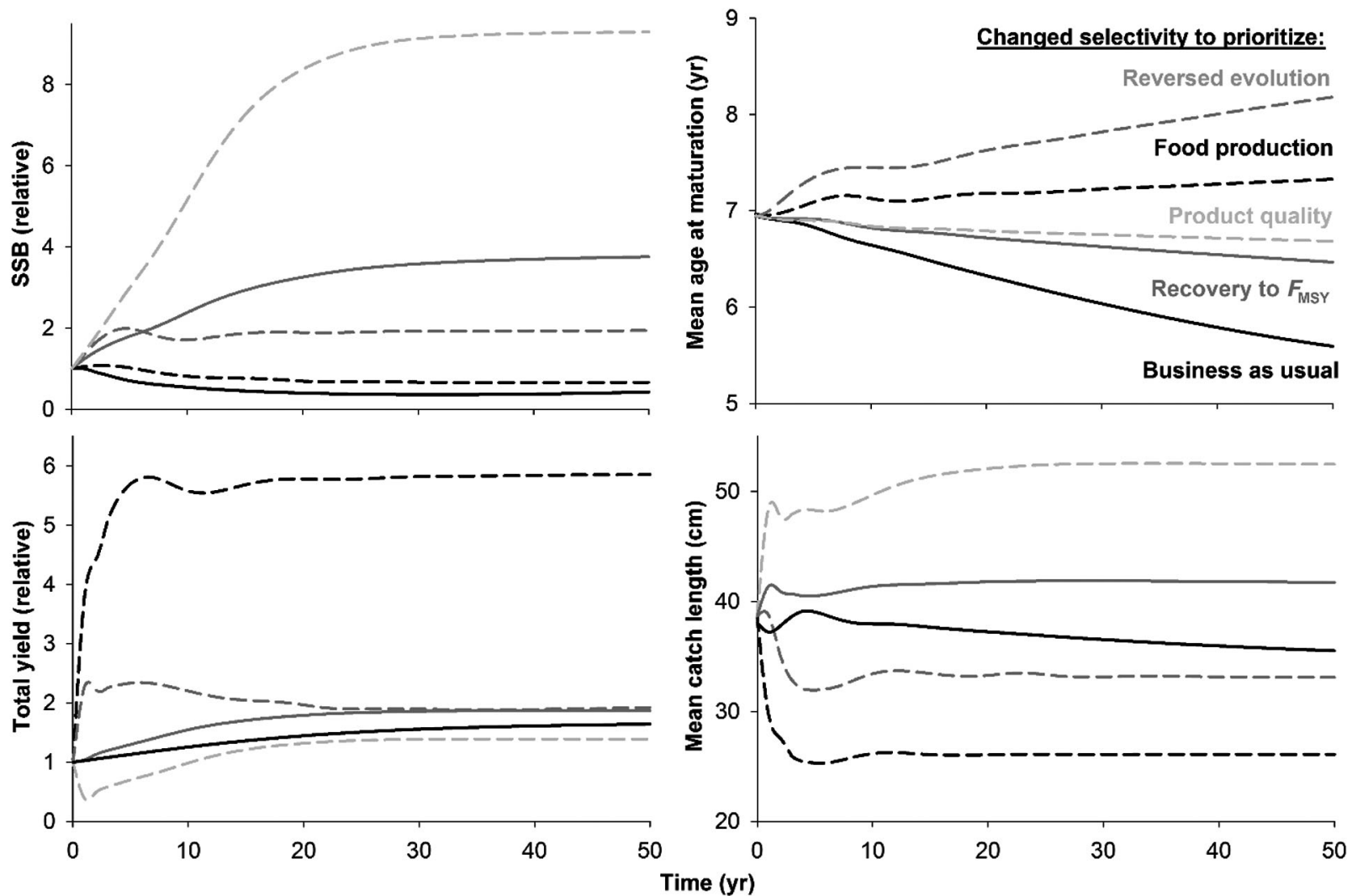

Fig. 3. Spawning stock biomass (SSB), mean phenotypic maturation age, total yield and mean length of fish in the catch over $50 \mathrm{yr}$ for harvest scenarios with current policies and changed selectivity to prioritize alternative objectives. Scenarios include overfishing with historic fishing mortality ('business as usual': solid black line; input fishing mortality $F_{\text {input }}=0.55$, size selectivity $L_{\max }=60 \mathrm{~cm}$ and gillnet proportion $o=0$ ), a maximum sustainable yield (MSY) policy with current selectivity ('recovery to $F_{\mathrm{MSY}}$ ': solid grey line; $F_{\text {input }}=0.35, L_{\max }=60 \mathrm{~cm}$ and $o=0$ ), increasing food production through high total yield ('food production': dashed black line; $F_{\text {input }}=0.55, L_{\max }=40 \mathrm{~cm}$ and $o=0.75$ ), reversing evolutionary impacts ('reversed evolution': dashed grey line; $F_{\text {input }}=0.8, L_{\max }=60 \mathrm{~cm}$ and $o=1$ ) and generating high product quality represented by large fish sizes in the catch ('product quality': dashed light grey line; $F_{\text {input }}=0.2, L_{\max }=80 \mathrm{~cm}$ and $o=0.5$ ). SSB and total yield are standardized to the starting values at $t=0 \mathrm{yr}$

ing feasible in practice (Fig. 3). As key objectives, we defined the following: large biomass of catch and thus food production (achieved with $F_{\text {input }}=0.55$, $L_{\max }=40 \mathrm{~cm}$ and $o=0.75$ ); high fish quality represented by large catch sizes $\left(F_{\text {input }}=0.2, L_{\max }=80 \mathrm{~cm}\right.$ and $o=0.5$ ); and increasing maturation age to reverse evolutionary impacts $\left(F_{\text {input }}=0.8, L_{\max }=60 \mathrm{~cm}\right.$ and $o=1$ ). These were contrasted with a MSY policy $\left(F_{\text {input }}=0.3, L_{\max }=60 \mathrm{~cm}\right.$ and $\left.o=0\right)$ and continued overfishing $\left(F_{\text {input }}=0.55, L_{\max }=60 \mathrm{~cm}\right.$ and $\left.o=0\right)$ under current selectivity. As our simulations started from a stock partially adapted to intense exploitation, released fishing pressure $\left(F_{\text {input }}<0.55\right)$ had immediate and positive ecological effects and mostly resulted in increasing biomass and slowed or reversed evolution of maturation age, which over time further transformed population dynamics and yield. Similarly, positive effects occurred when changing from trawl- like to gillnet selectivity, and were stronger when small fish were targeted (low $L_{\max }$ ) and fishing intensity was high (high $F_{\text {input }}$ ). Over all simulated harvest strategies, there was a clear trade-off between maximizing total yield and product quality, while the objective of reversing evolution aligned with high food production in a zone of consensus (Fig. 4).

The qualitative patterns of the results remained stable over a wide range of different parameter values, model structures and initial stock sizes. Alternative models with $o$ as a simple proportion of $F_{\text {input }}$ or with constant natural mortality, did not notably affect predictions; nor did a sensitivity analysis with a variation of $\pm 20 \%$ for all parameter values (not shown). Models without evolution were similar in the short run but deviated more over time. Changing parameter values primarily influenced quantitative outcomes by up- or downscaling the numer- 


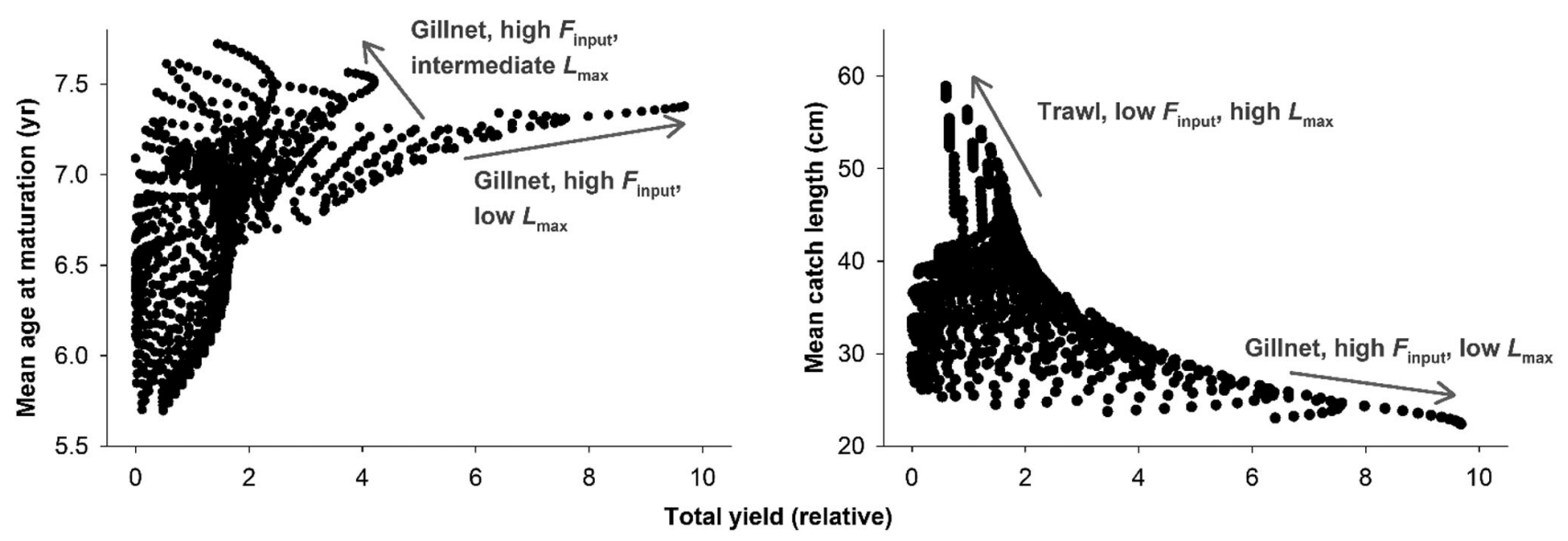

Fig. 4. Endpoints of total yield compared to endpoints of (a) mean age at maturation and (b) mean length of fish in catch after 20 yr. Each point represents 1 simulation after $100 \mathrm{yr}$ with a specific set of gillnet proportion $o$, size selectivity $L_{\max }$ and fishing mortality $F_{\text {input. }}$ Specifications of management strategies that achieve the objectives of maximizing total yield, mean age at maturation or mean catch size are indicated. Total yield is standardized to the starting values at $t=0 \mathrm{yr}$

ical outcomes. Typically, highest sensitivity was observed for parameters affecting growth and natural mortality.

\section{DISCUSSION}

The combined choice of fishing mortality, gear type and target size influences size and structure of a fish stock, including yield and its qualities and how traits evolve over time. Which fishing regime performs best depends on the specific management objectives; however, our results illustrate that gillnet-type domeshaped selectivity curves can counteract detrimental effects of classical harvesting strategies and create a consensus area among major objectives, namely sustainable yield maximization and stock conservation. Across all our simulations, pure gillnet selectivity combined with a low target size and high fishing mortality generated the highest values of SSB and yield, and increased age at maturation. These beneficial changes for an overfished stock occurred relatively quickly, over time spans of several years, and became more intensified in the long run. This suggests that evolutionary impacts may be managed with relatively simple gear regulations, increasing fisheries yield even in the short run.

As classic management policies suggest, high size selectivity minimized the harvest rate for young, small fish, which allowed them to spawn and sustain the stock even under high fishing pressure, a situation that otherwise could have led to collapse. Low size selectivity $\left(L_{\max }=40 \mathrm{~cm}\right)$ in combination with an increasingly dome-shaped selectivity curve created a similar refuge, but in this case large and old individ- uals benefitted from reduced harvest rate (with a pure gillnet selectivity they may even be entirely excluded from fishing). The higher survival rate of big, fecund individuals increased, thus resulting in the highest productivity and yield over all fishing scenarios. This effect was driven by the relationship between size and fecundity and therefore occurred independently of potential maternal effects or evolutionary change. This is in contrast to most current management situations, where predominantly trawling (low o) combined with low size selectivity makes the entire stock vulnerable to fishing, resulting in low productivity, even under low fishing pressure.

Fishing reduces individual survival probabilities and thus alters the selection landscape on life-history traits such as age at maturation, potentially resulting in negative effects for fish stocks and fisheries (Law \& Grey 1989, Heino 1998, Jørgensen \& Fiksen 2010). Because such consequences are an inevitable result of fishing, low harvesting mortalities and thus lower catches have been suggested as the general remedy against fishing-induced evolution (Heino 1998, Law 2000, Laugen et al. 2014). Our results align with this prediction, but only when trawls dominate the fishery. However, here we show that the extent of these changes can be heavily influenced by the selectivity regime, either beneficially or detrimentally for the fish stock and the fishery. This aligns with previous findings from studies on Chinook salmon (Hard et al. 2009), Atlantic cod (Hutchings 2009, Jørgensen et al. 2009, Kuparinen et al. 2009), northern pike (Matsumura et al. 2011) and North Sea plaice (Mollet et al. 2016), indicating that the observations are robust over different model designs and parameterizations. Here we expand on these results and use assump- 
tions of quantitative genetics to quantify likely rates of changes, showing that introducing gillnet selectivity into a gear mix may have surprisingly strong and rapid positive effects on maturation evolution and stock productivity. This adds to the existing literature a management-orientated perspective on changes within short time frames, demonstrating that appropriately designed gear selectivity can create a consensus between evolutionary and non-evolutionary management objectives.

A key contribution of the present study to the literature is to include temporal effects of mixed gear types into the analysis, which allows for more nuanced short-term predictions relevant for fisheries managers. Our results underline that fishing inevitably has evolutionary impacts, yet the direction and degree of these impacts are driven by the fishing selectivity. This confirms expectation and results from previous studies but goes further in laying out alternative management options on timescales that matter for fisheries managers, stakeholders and industry. Furthermore, our results show that mitigation or reversal of evolutionary impacts and maximizing yield are not trade-offs, but can be achieved with similar harvesting strategies, providing a zone of consensus for these 2 major objectives.

Minimum size limits and similar restrictions aimed at enabling fish to grow and reproduce are a paradigm of fisheries management, yet such size selectivity may cause or contribute to undesirable evolutionary impacts of fishing (Law 2007, Jørgensen et al. 2009, Laugen et al. 2014). Our results demonstrate that shifting selectivity regimes to lower size thresholds and dome-shaped selectivity curves can reverse these impacts and improve fishing output. Furthermore, adjusting size selectivity towards lower sizes and dome-shaped selectivity curves increases the resilience to high fishing pressure, therefore reducing the need for accurate management advice on adequate fishing mortality, potentially paving the way for more cost-efficient management processes (Zimmermann \& Enberg 2016). To use size selectivity that better accounts for the life history of the fished species may therefore not only be recommend to manage fishing-induced evolution but also to achieve both key objectives of improved sustainability and increased yield. The underlying mechanism is reduced mortality for bigger, older individuals, creating a size refuge for the stock component that may contribute disproportionately to the productivity and stability of many fish stocks (Berkeley et al. 2004a, Birkeland \& Dayton 2005, Hixon et al. 2014). Protecting these may therefore increase yield and sustain- ability, and provide fitness benefits for investing in growth, resulting in selection towards higher maturation ages and larger size. High fishing pressure on low target sizes with dome-shaped selectivity achieved this and re-established a more pristine population structure. Hence, the results of our model agree partly with management concepts of less size selectivity to re-establish pre-fishing population structure (Zhou et al. 2010, Garcia et al. 2012) as well as more size selectivity to engineer the most productive population structure of a stock (Froese 2004, Diekert 2013). Ideas from both these approaches may therefore highlight alternative paths to sustainable fisheries. This demonstrates that stock-specific adjustments of selectivity curves are a suitable management tool to achieve and potentially combine various key objectives of fisheries, but may result in new trade-offs with other management objectives.

The predictions of the model may be limited by simplifying biological, economic and technical assumptions. Using age at maturation as the only evolving trait that determines growth ignores the fact that growth results from a complex interplay with various other life-history traits that may also evolve (Enberg et al. 2012) and affect the outcome of specific management strategies. The growth capacity or reproductive investment, for instance, may decrease or increase depending on the specific harvest strategy (Dunlop et al. 2009), attenuating or intensifying the outcome of particular scenarios in this study. Similarly, over-compensatory recruitment dynamics and intercohort competition are common in many commercial stocks (Fogarty et al. 1991, Ricard et al. 2016) and may diminish the benefits of a large stock size. Furthermore, to select or exclude particular size classes can be challenging, although gear design or fishing strategies, i.e. the temporal or spatial distribution of fishing effort, may help to approximate the desired dome-shaped selectivity, for instance through trawl modifications (Madsen \& Valentinsson 2010, Stepputtis et al. 2016) or reduced fishing during spawning season (Rijnsdorp et al. 2012). Additionally, there are economic drivers of size-selective fishing that may affect fleet dynamics and management objectives, particularly when gear-specific cost of fishing effort or size-dependent prices (Zimmermann \& Heino 2013, Asche et al. 2015) influence economically optimal harvesting strategies (Tahvonen 2009, Zimmermann et al. 2011). However, higher abundances in lower size ranges may counteract this effect through increased catch per unit effort. Further bioeconomic studies may provide insights on potential economic consequences of such gear regulations. 
Acknowledgements. The authors acknowledge funding from the University of Bergen and the Research Council of Norway (184951/S40, 243735 [ConEvolHer] and 255530 [MESSAGE]).

\section{LITERATURE CITED}

Asche F, Chen Y, Smith MD (2015) Economic incentives to target species and fish size: prices and fine-scale product attributes in Norwegian fisheries. ICES J Mar Sci 72: 733-740

Berkeley SA, Chapman C, Sogard SM (2004a) Maternal age as a determinant of larval growth and survival in a marine fish, Sebastes melanops. Ecology 85:1258-1264

Berkeley SA, Hixon MA, Larson RJ, Love MS (2004b) Fisheries sustainability via protection of age structure and spatial distribution of fish populations. Fisheries (Bethesda, MD) 29:23-32

*Birkeland C, Dayton P (2005) The importance in fishery management of leaving the big ones. Trends Ecol Evol 20:356-358

Boukal DS, Dieckmann U, Enberg K, Heino M, Jørgensen C (2014) Life-history implications of the allometric scaling of growth. J Theor Biol 359:199-207

* Chan KMA, Satterfield T, Goldstein J (2012) Rethinking ecosystem services to better address and navigate cultural values. Ecol Econ 74:8-18

* Chiesura A, de Groot R (2003) Critical natural capital: a socio-cultural perspective. Ecol Econ 44:219-231

Cochrane KL, Garcia SM (2009) A fishery manager's guidebook. Wiley-Blackwell, Hoboken, NJ

* Conover DO, Munch SB (2002) Sustaining fisheries yields over evolutionary time scales. Science 297:94-96

* Costello C, Ovando D, Clavelle T, Strauss CK and others (2016) Global fishery prospects under contrasting management regimes. Proc Natl Acad Sci USA 113:5125-5129

* Dayton PK, Thrush SF, Agardy MT, Hofman RJ (1995) Environmental effects of marine fishing. Aquat Conserv 5: 205-232

Diekert FK (2013) The growing value of age: exploring economic gains from age-specific harvesting in the Northeast Arctic cod fishery. Can J Fish Aquat Sci 70: 1346-1358

Dunlop ES, Heino M, Dieckmann U (2009) Eco-genetic modeling of contemporary life-history evolution. Ecol Appl 19:1815-1834

Enberg K, Jørgensen C, Dunlop E, Heino M, Dieckmann U (2009) Implications of fisheries-induced evolution for stock rebuilding and recovery. Evol Appl 2:394-414

*Enberg K, Jørgensen C, Dunlop ES, Varpe Ø and others (2012) Fishing-induced evolution of growth: concepts, mechanisms and the empirical evidence. Mar Ecol (Berl) $33: 1-25$

Erb KH, Lauk C, Kastner T, Mayer A, Theurl MC, Haberl H (2016) Exploring the biophysical option space for feeding the world without deforestation. Nat Commun 7:11382

FAO (2014) The state of world fisheries and aquaculture 2014. FAO Fisheries and Aquaculture Department, Rome

FAO (2016) The state of world fisheries and aquaculture 2016. FAO Fisheries and Aquaculture Department, Rome

Finley C, Oreskes N (2013) Maximum sustained yield: a policy disguised as science. ICES J Mar Sci 70:245-250

Fogarty MJ, Sissenwine MP, Cohen EB (1991) Recruitment variability and the dynamics of exploited marine popula- tions. Trends Ecol Evol 6:241-246

Francis R, Hixon M, Clarke M, Murawski S, Ralston S (2007) Ten commandments for ecosystem-based fisheries scientists. Fisheries (Bethesda, MD) 32:217-233

* Froese R (2004) Keep it simple: three indicators to deal with overfishing. Fish Fish 5:86-91

* Garcia SM, Kolding J, Rice J, Rochet MJ and others (2012) Reconsidering the consequences of selective fisheries. Science 335:1045-1047

Gislason H (1994) Ecosystem effects of fishing activities in the North Sea. Mar Pollut Bull 29:520-527

* Gislason H, Daan N, Rice JC, Pope JG (2010) Size, growth, temperature and the natural mortality of marine fish. Fish Fish 11:149-158

* Hamley JM (1975) Review of gillnet selectivity. J Fish Res Board Can 32:1943-1969

Hard JJ, Eldridge W, Naish KA (2009) Genetic consequences of size-selective fishing: implications for viability of Yukon River Chinook salmon in the Arctic-YukonKuskokwim region of Alaska. Proc Am Fish Soc Symp 70: $759-780$

* Heino M (1998) Management of evolving fish stocks. Can J Fish Aquat Sci 55:1971-1982

*Heino M, Baulier L, Boukal DS, Ernande B and others (2013) Can fisheries-induced evolution shift reference points for fisheries management? ICES J Mar Sci 70:707-721

*Hilborn R (2007) Defining success in fisheries and conflicts in objectives. Mar Policy 31:153-158

Hixon MA, Johnson DW, Sogard SM (2014) BOFFFFs: on the importance of conserving old-growth age structure in fishery populations. ICES J Mar Sci 71:2171-2185

*Hsieh CH, Reiss CS, Hunter JR, Beddington JR, May RM, Sugihara G (2006) Fishing elevates variability in the abundance of exploited species. Nature 443:859-862

*Huse I, Løkkeborg S, Soldal AV (2000) Relative selectivity in trawl, longline and gillnet fisheries for cod and haddock. ICES J Mar Sci 57:1271-1282

*Hutchings JA (2009) Avoidance of fisheries induced evolution: management implications for catch selectivity and limit reference points. Evol Appl 2:324-334

Hutchings JA, Fraser DJ (2008) The nature of fisheries-and farming-induced evolution. Mol Ecol 17:294-313

ICES (International Council for the Exploration of the Sea) (2015) Report of the Arctic Fisheries Working Group (AFWG). Book ICES CM 2015/ACOM:05. ICES, Copenhagen

Jennings S, Kaiser MJ (1998) The effects of fishing on marine ecosystems. In: Blaxter JHS, Southward AJ, Tyler PA (eds) Advances in Marine Biology, book 34. Academic Press, Cambridge, MA

Jørgensen C, Fiksen $\varnothing$ (2010) Modelling fishing-induced adaptations and consequences for natural mortality. Can J Fish Aquat Sci 67:1086-1097

Jørgensen C, Enberg K, Dunlop ES, Arlinghaus R and others (2007) Managing evolving fish stocks. Science 318: 1247-1248

Jørgensen C, Ernande B, Fiksen Ø (2009) Size selective fishing gear and life history evolution in the Northeast Arctic cod. Evol Appl 2:356-370

KKuparinen A, Merilä J (2007) Detecting and managing fisheries-induced evolution. Trends Ecol Evol 22:652-659

Kuparinen A, Kuikka S, Merilä J (2009) Estimating fisheries induced selection: traditional gear selectivity research meets fisheries induced evolution. Evol Appl 2:234-243

K Kvamme C, Isaksen B (2004) Total selectivity of a commer- 
cial cod trawl with and without a grid mounted: grid and codend selectivity of North-east Artic cod. Fish Res 68: 305-318

Larkin PA (1977) An epitaph for the concept of maximum sustained yield. Trans Am Fish Soc 106:1-11

Laugen AT, Engelhard GH, Whitlock R, Arlinghaus R and others (2014) Evolutionary impact assessment: accounting for evolutionary consequences of fishing in an ecosystem approach to fisheries management. Fish Fish 15: 65-96

Law R (2000) Fishing, selection, and phenotypic evolution. ICES J Mar Sci 57:659-668

Law R (2007) Fisheries-induced evolution: present status and future directions. Mar Ecol Prog Ser 335:271-277

Law R, Grey DR (1989) Evolution of yields from populations with age-specific cropping. Evol Ecol 3:343-359

Law R, Plank MJ, Kolding J (2012) On balanced exploitation of marine ecosystems: results from dynamic size spectra. ICES J Mar Sci 69:602-614

Lynch M, Walsh B (1998) Genetics and analysis of quantitative traits. Sinauer Associates, Sunderland, MA

Madsen N, Valentinsson D (2010) Use of selective devices in trawls to support recovery of the Kattegat cod stock: a review of experiments and experience. ICES J Mar Sci 67:2042-2050

Matsumura S, Arlinghaus R, Dieckmann U (2011) Assessing evolutionary consequences of size-selective recreational fishing on multiple life-history traits, with an application to northern pike (Esox lucius). Evol Ecol 25:711-735

Mollet FM, Poos JJ, Dieckmann U, Rijnsdorp AD (2016) Evolutionary impact assessment of the North Sea plaice fishery. Can J Fish Aquat Sci 73:1126-1137

Murawski S, Rago P, Trippel E (2001) Impacts of demographic variation in spawning characteristics on reference points for fishery management. ICES J Mar Sci 58: 1002-1014

* Ottersen G, Hjermann DØ, Stenseth NC (2006) Changes in spawning stock structure strengthen the link between climate and recruitment in a heavily fished cod (Gadus morhua) stock. Fish Oceanogr 15:230-243

Quince C, Abrams PA, Shuter BJ, Lester NP (2008) Biphasic growth in fish I: theoretical foundations. J Theor Biol 254: 197-206

Ricard D, Zimmermann F, Heino M (2016) Are negative

Editorial responsibility: Jake Rice,

Ottawa, Ontario, Canada intra-specific interactions important for recruitment dynamics? A case study of Atlantic fish stocks. Mar Ecol Prog Ser 547:211-217

Rijnsdorp A (1993) Fisheries as a large-scale experiment on life-history evolution: disentangling phenotypic and genetic effects in changes in maturation and reproduction of North Sea plaice, Pleuronectes platessa L. Oecologia 96:391-401

* Rijnsdorp AD, Overzee HMJ, Poos JJ (2012) Ecological and economic trade-offs in the management of mixed fisheries: a case study of spawning closures in flatfish fisheries. Mar Ecol Prog Ser 447:179-194

Stepputtis D, Santos J, Herrmann B, Mieske B (2016) Broadening the horizon of size selectivity in trawl gears. Fish Res 184:18-25

* Tahvonen O (2009) Optimal harvesting of age-structured fish populations. Mar Resour Econ 24:147-169

UNCLOS (1982) United Nations convention on the law of the sea. Book 1833 UNTS 3, United Nations, Geneva

United Nations (2002) Johannesburg declaration on sustainable development. Book A/CONF.199/20. United Nations World Summit on Sustainable Development, Johannesburg

Watson R, Revenga C, Kura Y (2006) Fishing gear associated with global marine catches: I. Database development. Fish Res 79:97-102

K Zhou S, Smith ADM, Punt AE, Richardson AJ and others (2010) Ecosystem-based fisheries management requires a change to the selective fishing philosophy. Proc Natl Acad Sci USA 107:9485-9489

Zimmermann F, Enberg K (2016) Can less be more? Effects of reduced frequency of surveys and stock assessments. ICES J Mar Sci https://doi.org/10.1093/icesjms/fst121

Zimmermann F, Heino M (2013) Is size-dependent pricing prevalent in fisheries? The case of Norwegian demersal and pelagic fisheries. ICES J Mar Sci 70:1389-1395

Zimmermann F, Jørgensen C (2015) Bioeconomic consequences of fishing-induced evolution: a model predicts limited impact on net present value. Can J Fish Aquat Sci 72:612-624

Zimmermann F, Heino M, Steinshamn SI (2011) Does size matter? A bioeconomic perspective on optimal harvesting when price is size-dependent. Can J Fish Aquat Sci 68:1651-1659

Submitted: August 18, 2016; Accepted: November 21, 2016 Proofs received from author(s): January 11, 2017 